\title{
Education and training in optics and photonics in Brazil
}

\section{Cid de Araújo}

Cid B. de Araújo, "Education and training in optics and photonics in Brazil," Proc. SPIE 9663, Eighth International Topical Meeting on Education and Training in Optics and Photonics, 96631E (6 October 2003); doi: 10.1117/12.2208464

SPIE Event: Eighth International Topical Meeting on Education and Training in Optics and Photonics, 2003, Tucson, Arizona, United States 


\title{
Education and training in optics and photonics in Brazil
}

\author{
Cid B. de Araújo \\ Departamento de Física, Universidade Federal de Pernambuco, Cidade Universitária, 50670-901 Recife, PE, Brazil \\ telephone: +55813271-8450; fax: 55-81-32710359; e-mail: cid@df.ufpe.br
}

\begin{abstract}
An overview of educational, training, and research activities as well as the capacity building of Brazilian institutions in the Optics and Photonics area is presented. Data collected from active research and teaching groups allow a detailed evaluation of the present situation. (C)2003 Optical Society of America

OCIS codes: (000.2060) Education; (000.1780) Conferences, lectures, and institutes
\end{abstract}

Education and training in Optics and Photonics (O\&P) in Brazil dates back to the fifties. Many Brazilian researchers such as Sergio P. S. Porto, who made historical contributions to Laser Spectroscopy in the sixties working at the Bell Labs, got their basic education in Optics in Brazil. Other distinguished Brazilian scientists that became internationally recognized also had their basic education in Brazil before accepting jobs in Europe and the US. For instance, the first Brazilian He-Ne laser was built in the Universidade Federal do Rio Grande do Sul in 1964 while other laboratories were initiated in Rio de Janeiro and São Paulo also in the sixties.

Thanks to the growth of graduate courses in Science and Engineering in the seventies, the academic activities in Optics grew in various parts of the country. Very important for the development of the research and teaching (R\&T) in Optics was the creation of the University of Campinas in São Paulo, which has been generously supported by the Government since 1970. On the other hand, the beginning of activities in O\&P in the Universidade Federal de Pernambuco at Recife in 1971 was an important step towards the decentralization of R\&T in Brazil. In the past 25 years, new laboratories were founded in various states. It is worth mentioning new laboratories at Minas Gerais, Alagoas and Paraíba. In recent years the number of Brazilians post-graduates experienced a fast growth rate $(\approx 10 \%$ per year). In 2002, for example, 6000 Doctors of Science graduate in all areas of Science, with more than 200 in Physics.

Presently, education and training in O\&P is spread across the country in Universities that offer programs in Physics. Few non-university laboratories in São Paulo and Rio de Janeiro have O\&P research groups, which also run educational programs. It can be noticed that there is an effort to match the academic activities with the production standards of the best research groups in the world. Therefore, most of the scientific articles are published in the best periodicals worldwide and according to INSPEC, more than $40 \%$ of the citations to Latin American (L.A.) opticians are to Brazilian researchers [1]. The stronger research groups have graduate students working in areas such as optical materials, nonlinear optics, quantum optics and quantum information, laser cooling and trapping, optical fibers and glasses for photonics.

The optics industry developed in the past 30 years is concentrated in São Paulo, which hosts most of the high technology companies. In São Carlos and Campinas, the optoelectronic industry established successful companies thanks to groups of physicists from local universities; furthermore, R\&T groups from the University of Campinas have partnerships with the telecommunication industry in optical fibers, lasers and optical amplifiers. O\&P groups in Recife, Rio de Janeiro, São Carlos and Rio Grande do Sul have joint projects with telecommunication industry and companies in the fields of optical sensors and medical instrumentation. The companies that have Optics as their main activity produce optical components and equipments for medical applications, sensors, optical fibers, and integrated optics components for optical communications. Some international companies have R\&D laboratories in Brazil, but the number of researchers employed is still small. Training of technicians occurs in a small scale. Most of the programs are offered by the R\&T groups from the Universities but there are few technical schools that introduced O\&P in their courses in recent years.

The O\&P community meets every year in the National Conference of Condensed Matter Physics that congregates more than 1000 participants. The Optics Section in this conference is attended by $\approx 200$ participants but other Solid State Physics Sections include themes related to laser spectroscopy of materials. The Brazilian Physical Society (SBF) promotes every two years, since 1986, a two-week summer school on Nonlinear Optics and Quantum Optics with invited Brazilian and international distinguished speakers. Attendees from other L.A. countries also participate. Researchers in O\&P participate in two national scientific societies: the SBF and the Microwave and 
Optoelectronic Brazilian Society, with most of their members being engineers. Both societies promote annual national scientific and technical meetings.

A set of tables and figures with data related to R\&T activities in O\&P in Brazil will be presented in this communication. Prospects for future activities, new research areas, special courses for technicians, and cooperative projects between O\&P groups and industries will be discussed.

[1] South and Latin America Data Mining Analysis Project Report, Office of Naval Research International Liaison Office (March, 2002).

Proc. of SPIE Vol. $966396631 \mathrm{E}-2$ 